tives to prediction and retrodiction as tests of the 'fitness' of hypotheses. What forms could 'diction' take? In what sense were the micro-particles of physics to be regarded as 'ultimate' or 'fundamental' ? What exactly was meant by saying that one science or one branch of a science was 'reducible' to another ? These were some of the many questions raised and left not wholly answered.

The Vice-Chancellor of the University of Bristol kindly invited the members to a sherry party at
Wills Hall on the Saturday evening. Thereafter, small informal groups, oblivious to everything except their own intense discussion, seemed to be generated spontaneously in all the many pleasant corners of Wills Hall and its gardens. At the conclusion of a stimulating week-end, expressions of thanks to the hosts at the University of Bristol, to the staff of Wills Hall and to the organizing secretary were more than mere formalities.

\title{
THE NATIONAL RESEARCH COUNCIL OF CANADA
}

$\mathrm{T}$ HE forty-third annual report of the National Research Council of Canada, covering the year 1959-60, includes besides the report of the president, Dr. E. W. R. Steacie, of the nine divisions, two regional laboratories and the National Aeronautical Establishment and the financial statement, the annual report of Canadian Patents and Development, Ltd.*.

During the year the Council provided 8.7 million dollars in support of pure research in the universities, compared with $6 \cdot 3$ million dollars in 1958-59, of which 84 per cent was for 875 research grants and the remainder for 425 postgraduate scholarships, fellowships and associateships. The Council's scientific research staff of 658 included 137 postdoctorate Fellows, and in addition 916 technical personnel and 866 general service and administrative staff were employed. Claiming that neither the United States nor the United Kingdom possesses the clear but flexible delineation of administrative authority for science that exists in Canada, Dr. Steacie suggests that in Canada the responsibilities of the Minister for Science are constitutionally exercised by the chairman of the Privy Council Committee on Scientific and Industrial Research, and that in this respect Canada is forty years ahead of the United Kingdom. The problem in Canada is to ensure that scientific activities are so organized as to encourage the full development of the scientific and technical resources of the country. The first responsibility of a national science policy must be support of research in the universities, and the problem is how to maintain the strength and depth of the university science departments and, at the same time, satisfy the requirements of defence, industry and development of national resources with the vigour and competence demanded by international competition, without over-emphasizing technology at the expense of other activities. Dr. Steacie, noting that the Research Council has proved in the past to be an effective channel for supporting science in the universities, urges the need for a continual review of the support of science in the universities to ensure that procedures continue to evolve with the growth of science and changes in administrative practice. Further, while in Canada those departments of Government with administrative responsibilities for natural resources are responsible for the basic research to support their programmes, the Research Council has the function of ensuring the general adequacy of all remaining basic research, but Dr. Steacie stresses the importance of backing

* Forty-third Annual Report of the National Research Council of Canada, 1959-60, including the Annual Report of Canadian Patent and Development, Limited. (N.R.C. No. 5665.) Pp. 40. (Ottawa: Queen's Printer, 1960.)
Canadian industry by an industrial research effort as great as the scientific resources of the country can support.

Of the work of the Division of Applied Biology, the report notes a co-operative project with the Department of Agriculture on the design and performance of jacketed cold-storage rooms requiring fundamental knowledge of the factors determining low-velocity airflow through shallow ducts, and a study by the Biometrics Section of agricultural meteorology as an extension of the statistical study of protein variability in wheat and wheat exports. Preparations were begun, including design of equipment, for an international expedition to study adaptation to cold by Eskimos. The work of the Division of Applied Chemistry on metals has gradually expanded during recent years, and now includes investigations of the effect of composition and structure on the optical and magnetic properties of a wide variety of alloys. A new technique, developed by the Division about eight years ago for the contacting of fluids and solids, has now been put into commercial operation in grain drying. The Division of Pure Chemistry has shown that ionization potentials of radicals prepared by pyrolytic reactions can be measured by electron impact in the mass spectrometer, and a study of the diffusion of chloride ions in single crystals of sodium chloride and of potassium chloride has shown that the diffusion is very sensitive to the presence of gross imperfections such as dislocations and grain boundaries in the crystals, while attempts to correlate the accumulated observations in the photo-oxidation of ketones have led to the conclusion that not only the rate but also the nature of the products of the reactions of methyl radicals with oxygen depend on the total pressure in the system as well as the presence of molecules containing easily abstractable hydrogen.

In the Division of Applied Physics a new group has been established for plasma research, work was completed in the interferometry laboratory which contributed to an international agreement to base the unit of length, the international metre, on a particular wave-length of the spectrum of an isotope of krypton, and the experiment to determine $g$, the acceleration due to gravity, by direct observations on a falling body was completed. The group in the Division of Pure Physics concerned with cosmic ray work is still devoting much of its efforts to international co-operation of the type started during the International Geophysical Year, and the development of a space research programme in Canada has permitted cosmic ray measurements with rockets flown to high altitudes. In the $\mathrm{X}$-ray diffraction laboratory 
important results are being obtained in the crystal chemistry of vanadium minerals and the stereochemistry and absolute configuration are being established for certain narcotics the structural formula of which have long been in dispute.

The Division of Mechanical Engineering records increasing emphasis on longer term investigations in thermodynanics and engine evolution, and many new propulsion problems in air transport are also being studied, especially those arising from vertical takeoff and landing, while certain fluid mechanical aspects of nuclear reactors are being examined. At the National Aeronautical Establishment a substantial research effort has been redirected to problems of high-speed and very high-speed flight, and in particular an increasing effort is being applied to problems arising from very high temperatures. Much of the work of the Radio and Electrical Engineering Division was concerned with defence projects, but the remainder of the programme was concerned with fundamental problems in electrical engineering and electronics, and a pressure gauge capable of measuring the atmospheric pressure at satellite altitudes was developed.

Work at the Prairie Regional Laboratory, Saska. toon, is devoted to a more thorough understanding of the plants and micro-organisms growing on the prairies; but to promote the development of oil-seed crops as alternatives to cereal crops an intensive study of the chemical structure of glycerides was undertaken. At the Atlantic Regional Laboratory, Halifax, where the most efficient way of drying the commercially important plant materials of the region has been studied, a semi-commercial scale batch dryer was developed and a continuous dryer is now being designed and constructed in co-operation with industry.

\section{SAFETY OF YOUNG PEOPLE IN FACTORIES}

$\mathrm{P}^{\mathrm{n}}$ ROBABLY the most important chapter in the annual report of the Chief Inspector of Factories for 1959* is one of two chapters dealing with subjects of interest without being necessarily restricted to the events of the year-that dealing with the prevention of accidents to young persons. While the consistent downward trend in the number of fatal accidents continued in 1959, there was an increase in the number of reported accidents, and the Chief Inspector is disturbed at the increase in the number of accidents to young persons, from 9,838 in 1958 to 11,001 in 1959. This rise is not due just to an increase in the numbers employed, and indicates clearly that redoubled efforts will be necessary to hold the rate of accidents to young people in check, as increasing numbers of school-leavers enter industry in the coming years. The present drive to train young persons in safe working must be intensified, he writes, not only by industry but also by secondary and technical sehools and colleges.

The Chief Inspector, in his letter of presentation, points out that it is evident from the large number of accidents to the head and neck, to the feet and ankles and to the hands, that much more could be done to reduce such accidents by the wearing of suitable clothing, such as safety helmets, goggles, adequate footwear and gloves, and that careful attention would reduce dramatically the grand total of all reported industrial accidents. Young persons, particularly during the first year of employment, tend not to take adequate safety precautions and are more liable to run the risk of suffering injury than older workers. Ignorance of factory conditions and hazards, inexperience and natural curiosity, the desire to prove oneself, contempt for 'safety first' principles, liability to fatigue, and boredom leading to 'skylarking', can all be contributory factors, and there are many examples in the resorc's of the factory inspectorate of the kind of accident in which young. sters are concerned for such reasons.

Young persons, it is clear, enter employment with a handicap, and it is the responsibility of their employers to help them overcome it by providing * Ministry of Labour. Annual Report of the Chief Inspector of
Factories on Industrial Health, 1959. Pp. iii +60. (Cmnd. 1137.) (London : H.M. Stationery Office.) 3s. 6d. net. sound training and careful supervision and by insisting on high standards of obedience to safety rules. Many of the large firms have, in fact, built up excellent organizations for this purpose, and in his annual report for 1951 the Chief Inspector, Sir George Barnett, attributed the considerable reduction in the post-war accident-rate mainly to this factor. Many managements, however, did not trouble to make allowances, and since then the rate of decrease of accidents to young persons has slowed down, and the decrease in the number of accidents to young persons is, moreover, proportionately less than the corresponding decrease for all employed persons.

While there have been several important pieces of legislation since 1937 affecting young persons employed in factories, such as prohibition or restriction of employment in certain dangerous or unhealthy trades, prohibition of employment on certain types of dangerous machinery or in carrying or lifting excessive weights, limitation of the number of hours a young person may work and the provision of medical supervision, the legal contribution must be supplemented by effective training and supervision, beginning in schools and colleges and continuing in industry. There are few places where the young can be prepared for work in the factory so well as in secondary school and college workshops and housecraft rooms. Classes there provide an excellent opportunity for showing how tools should be main. tained and used, and machines properly guarded. The teacher, too, can inculcate a degree of safety consciousness and an acceptance of discipline in the correct use of machines and tools which is invaluable in factory life. As the Chief Inspector observed in addressing a conference on "Accident Prevention in Technical Colleges" at Blackpool in June 1958, arranged by the North West Regional Advisory Council for Further Education, his teachers are the best people to give the neophyte entering the factory the confidence that he requires.

The Chief Inspector did not suggest that safety should be taught as a subject per se, but rather that safety teaching should go hand in hand with the various subjects, and in the present report the Chief 